\title{
Study on the Dissemination of Red Literature \& Art of Xi' an and its English Translation Method Options in the Context of New Media
}

\author{
Sun Feiran \\ Xi’an Fanyi University, Xi’an, 710105, China
}

Keywords: red literature and art; dissemination; English translation; method

\begin{abstract}
In China, red literature and art are an important form and carrier to build and disseminate the red culture, exerting a huge influence on the spread and popularization of red culture. Xi'an is rich in red literature resources, and the inheritance and development of these resources have a decisive role in cultural construction and regional economic growth of Xi'an. This paper analyzes $\mathrm{Xi}$ 'an red literature and television series in the context of new media so as to find out the problems and put forward constructive suggestions for the dissemination and translation of red literature and art.
\end{abstract}

\section{Introduction}

Xi'an is not only an ancient Chinese capital known worldwide for its time-honored history and culture, but also a place where predecessors of proletarian revolution struggled for a new China. These long revolutionary traditions have left behind the rich red literature resources. Thus developing and publicizing the resources is the main part of the cultural development in Xi'an. Nowadays, "The Belt and Road" initiative provides the local cultural dissemination with new opportunities, an innovative mode of dissemination in the context of new media bringing the public original and practical ways of learning more local works of revolutionary literature and art, promoting the "Going-out" development strategy for the red culture and driving the development of tourism and social economy of Xi'an.

\section{Basic Concepts and Research Overview}

The new media, in contrast to the traditional one, is an emerging media form supported by the IT industry such as digital magazines and newspapers and touch media. Its speedy spreading, communication equality and strong interaction break the limitations of traditional media, achieving a fundamental change in information dissemination and providing a new environment for mass culture. That not only helps promote the communication between the scientific research and the industry development, but also bridges the cultural exchanges and progress between countries and regions.

With the progress of information technology, new media is becoming prior to the traditional one when the red literature and art are confronted with challenges and opportunities. The previous researches into the revolutionary works focus historically and politically on Chinese national quality and spirits carried on in the works and its effect of dissemination, or conduct a text analysis of one of classics. However, the study of its English translation in the context of new media is hardly done, except a few case studies from the perspectives of linguistic and translation theories.

\section{An Introduction to Red Literature and Art in Xi’an}

Red literature and art mainly refers to the literary and artistic works with the theme of presenting and praising the history of socialist revolution under the leadership of China's communist party. There are many excellent revolutionary writers and works in Xi'an. An enduring novel, Chuang Ye Shi was published after the native writer Liu Qing once had lived at Huangfu Village of Chang'an County for 14 years, when he knew all about the villagers and their life in the countryside. This 
helped him a lot portrait vivid characters in his writings. With a magnificent structure, the work fully shows the writer's powerful and vigorous writing style. In the period of new historical novels from the1980s to the 1990s, Chen Zhongshi in his novel of Bai Lu Yuan not only depicted rural life in a small village (the writer' birthplace), eastern suburb of Xi'an City, but also wrote about historical themes of war and revolution. And by giving a detailed account of life histories of two families (Bai and Lu), the writer shows the historical changes in the village during more than half a century from the late 19 century to the 1970s-1980s. Chen Zhongshi also wrote a short story -"Wa De Xin, Wa De Dan" (Children's Hearts and Bravery) in commemoration of the 60th anniversary of the Anti-Japanese War victory.

Besides the works mentioned above, Zhang Ye's novels, Wu Fu and Wan Chun, are also the representative of red literary works in Xi' an. Wu Fu is based on the historical event occurring on the eve of Shaanxi uprising after the Revolution of 1911, and the writer portrays the ordinary people's feelings and life during the special historical period and describes the revolutionary spirit deep in the human's soul. In Wan Chun he narrates the well-known battle of defending Xi'an in the time of the Republic of China, highlighting the value of the victory for the late Northern Expedition (1926-1928) and Xi'an Incident (1936). Mo Yan once commented: "Mr. Zhang Ye is the first writer of modern literature in Shaanxi. After $\mathrm{Wu} \mathrm{Fu}$, he created another pioneering masterpiece Wan Chun where we are exposed to the charming life and spirit embedded in the city's long history and cultural heritage.” Military writer Wang Lin wrote a novel named Chi Cha Feng Yun which presents historical reality by depicting a complete and realistic picture of the historical event-- Xi'an Incident. All these excellent works open a door for people to know more about Xi'an's history.

In the 21st century, dissemination methods of literature are diversified. Film and TV industry provides an opportunity for the spread of red literature \& art. Films and TV series derived from literary works emerge endlessly. For example, Bai $\mathrm{Lu}$ Yuan was adapted into the movie and TV dramas, and Wu Fu and Wan Chun respectively into TV series Shi Yue Wei Cheng and Guang Zhong Qiang Sheng, together with movies of Xi'an Incident, Special Mission and Gulu Ba Lights etc. But unfortunately, both literary works and these adapted products lack research in their English translation. When we retrieve on-line the key words "translation and dissemination, red literature and art, Xi'an” in the CNKI from 1980 to 2015, no result is found. When we type titles of some literary works in the search engine again, only10 articles are available, all the themes being related to Bai Lu Yuan, studying from the perspectives of folk, communication and culture. In fact, there has been no complete English version of Bai Lu Yuan, except a few research papers and translation fragments published on Chinese Translators Journal. Furthermore, English versions of other literary works cannot be found either, leaving a large room for the research and development in this field.

\section{Dissemination Strategies}

New media mode of dissemination overturns the traditional by its distinctive characteristics, such as equal disseminators, strong interactivity, and rapidity. Combining the new media with traditional one and giving full play to the advantages of new media can not only promote the dissemination of Xi' an red literature \& art, but also it can attract more readers. Therefore, with the advantages of new media as well as the traditional media, the rich red cultural resources in Xi'an will characterize as diversity, interactivity, high efficiency and popularity.

(1) We-media. As a part of new media, we-media represented by We-Chat, micro-blog etc. has broken the traditional one-way communication. In this circumstance, everyone is both the audience and disseminator, that is, everyone is a link of media. Thus, through this common and popular method, red culture will be more easily understood and accepted by the public. Furthermore, the way of acceptance by the public has also a directly effect on the speed of dissemination.

(2) We-Chat official accounts (Chinese-English). Due to its fast and wide-covered dissemination, and low cost, we-chat official accounts are very popular among institutions, organizations and individuals. Therefore, Xi'an red culture can be publicized with establishment of the bilingual official accounts.

(3) Chinese-English BBS and columns. Cooperation with well-known domestic and foreign web 
sites will enable BBS and columns to strengthen the publicity of red literary works so as to draw attention of the audiences worldwide.

(4) APP software. Mobile phones have nowadays become an indispensable communication tool in people's daily life. The news and APP software installed on phones can quickly and easily transmit the information of red literature and art to the public.

\section{English Translation Method Options}

In order to get Xi'an better understood by the world, bilingual dissemination has to be developed for various audiences, where accurate English translation is particularly important. We will illustrate translation method options from the following four aspects:

(1) Based on advantages of new media, we find that translations of short-length literary works, for example, short stories, novels, novellas, poetry and prose are much easier to be disseminated so that the public can catch the information in time.

(2) Different translation methods should be applied according to the length of works. When they render short-length works over the new media, translators are encouraged to use various methods such as selecting, condensing, adapting and other specific methods to improve the translation quality and achieve the best effect as long as the translator is loyal to the original.

(3) Since the English versions of revolutionary works, films and TV plays are in serious need, new media effectively provides a platform for researchers and translators when they are collecting information, discussing about works and sharing their experiences.

(4) Translators need professional training to enhance their comprehensive abilities. Xi'an is in a grave shortage of professional translators of red literature \& art. Most of them lack the knowledge of city's revolution history and its value. Moreover, many translators are not locals, so they may not really appreciate the essence of the Xi'an dialect when a work is written with local flavor, causing a big obstacle for dissemination.

\section{Conclusion}

As a kind of cultural heritage, red literature and art play an important role in modern society. In this information age, new media provides more options for its dissemination: on the one hand, putting forward the spirit of Xi'an' red culture, strengthening the patriotism education, promoting the region's red tourism and the social and economic development; on the other hand, enabling more young people and foreigners to get a complete picture of $\mathrm{Xi}$ 'an, enhancing the city image and influence in the world.

\section{Acknowledgements}

1) Project: “On the Dissemination of Red Literature \& Art of Xi' an and its English Translation Method Options” supported by 2016 Xi’an Social Science Planning Fund Project (No.16XF04)

2) Cultural Translation Research Team of Xi'an Fanyi University; Team Number: XFU17KYTDC10

\section{References}

[1] Chen Zhongshi. Bai Lu Yuan[M]. Beijing: People’s Literature Publishing House, 1993.

[2] Chen Zhongshi. Wa De Xin, Wa De Dan [J]. People’s literature, 2005(05): 30-36.

[3] Guo Lei, LiuShanshan. The Influence and Improvement of New Media on the Dissemination of Culture[J]. West China Broadcasting TV, 2015 (5):28.

[4] Huang Bin. The Red Culture Dissemination of Research in the New Media Environment[D]. Chongqing Jiaotong University, 2012.

[5] Liu Qing. Chuang Ye Shi[M]. Beijing: China Youth Publishing Group, 1960. 
[6] Liu Yongchun. On the development of red cultural resources and industrial transformation in Yantai[J]. Journal of Yantai Vocational College, 2010 (01): 16-20.

[7] Wang Lin. Chi Cha Feng Yun[M]. Shanghai: Shanghai Literature and Art Publishing Group, 1981.

[8] Yang Xiaoming. Tentative Translation of Bai Luyuan [J]. Chinese Translators Journal, 2013 (06):87-93.

[9] Zhang Ye. Wan Chun[M]. Beijing: The Writers Publishing House, 2009.

[10] Zhang Ye. Wu Fu[M]. Beijing: The Writers Publishing House, 2005. 